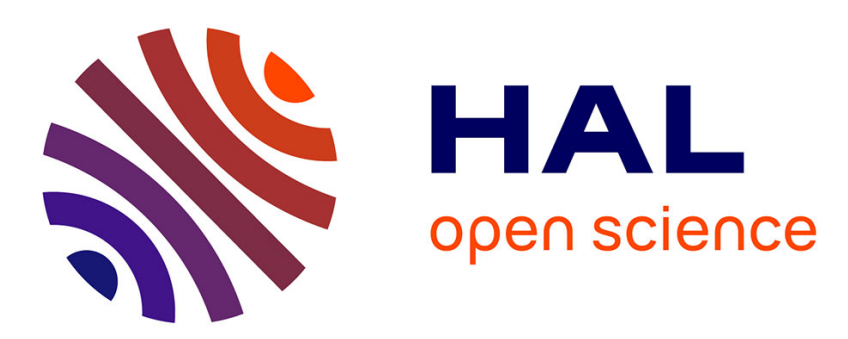

\title{
An In Situ Reflection Mode Quick Scanning EXAFS Study of Anodic Oxide Layer Formation on Silver
}

\author{
D. Hecht, P. Borthen, R. Frahm, H.-H. Strehblow
}

\section{To cite this version:}

D. Hecht, P. Borthen, R. Frahm, H.-H. Strehblow. An In Situ Reflection Mode Quick Scanning EXAFS Study of Anodic Oxide Layer Formation on Silver. Journal de Physique IV Proceedings, 1997, 7 (C2), pp.C2-717-C2-722. 10.1051/jp4:1997218 . jpa-00255247

\section{HAL Id: jpa-00255247 https://hal.science/jpa-00255247}

Submitted on 1 Jan 1997

HAL is a multi-disciplinary open access archive for the deposit and dissemination of scientific research documents, whether they are published or not. The documents may come from teaching and research institutions in France or abroad, or from public or private research centers.
L'archive ouverte pluridisciplinaire HAL, est destinée au dépôt et à la diffusion de documents scientifiques de niveau recherche, publiés ou non, émanant des établissements d'enseignement et de recherche français ou étrangers, des laboratoires publics ou privés. 


\title{
An In Situ Reflection Mode Quick Scanning EXAFS Study of Anodic Oxide Layer Formation on Silver
}

\author{
D. Hecht*, P. Borthen*, R. Frahm** and H.-H. Strehblow* \\ * Institut für Physikalische Chemie und Elektrochemie, Heinrich-Heine-Universität Düsseldorf, Universitätsstr. 1, \\ 40225 Diisseldorf, Germany \\ ** HASYLAB am DESY, Notkestr. 85, 22603 Hamburg, Germany
}

\begin{abstract}
The formation of anodic silver oxide layers was in situ investigated with time dependent extented X-ray absorption fine structure measurements in the external total reflection geometry. It is demonstrated for the first time that this EXAFS tool yielding near range order structural information about near surface regions is well suited for time resolved studies of electrode surfaces under electrochemical conditions. As examples, results obtained for the growth of oxide films on the silver surface are presented as well as changes of the near range order structure of $\operatorname{Ag}_{2} \mathrm{O}$-films induced by potentiostatic current transients.
\end{abstract}

\section{INTRODUCTION}

The growth of silver oxide layers has intensively been studied during the past. Cyclic voltammetry generally features two major anodic and two cathodic peaks which can be related to the formation and the reduction of $\mathrm{Ag}_{2} \mathrm{O}$ and $\mathrm{AgO}$, respectively (e.g. Refs. [1-3]). During the initial stages of the anodic oxidation of silver, an AgOH monolayer is formed [4, 5], followed by a thin primary $\operatorname{Ag}(\mathrm{I})$ oxide overlayer of monolayer coverage, which grows with increasing electrode potential [6,7]. While the secondary silver (I) oxide formed at more anodic potentials reveals a structure very similar to that of crystalline $\mathrm{Ag}_{2} \mathrm{O}$, the short range order structure of this primary oxide is strongly disordered, as shown by a previous extended $\mathrm{X}$-ray absorption fine structure (EXAFS) study [8]. Due to the large penetration of hard X-rays into matter, EXAFS is in general a bulk probe [9]. Like any other X-ray method, however, EXAFS can be made surface sensitive using the total external reflection geometry: Glancing angles below the critical angle of total reflection result in an X-ray penetration depth of some few $\mathrm{nm}[10,11]$. If appropriate electrochemical cells (e.g. Ref. [12]) are applied, experiments of this type can be performed in situ, i.e. problems with changes of electrochemically grown anodic films related to their emersion from the electrolyte and the loss of potential control are avoided.

In a conventional EXAFS experiment, the monochromator is moved in small energy steps from lower to higher energies in order to obtain a spectrum. Such a measurement scanning over $\approx 1000 \mathrm{eV}$ typically takes about $15-20$ minutes for bulk specimen and the investigation of diluted samples or the detection of reflectivity spectra often require acquisition times of more than one hour. Therefore such EXAFS experiments cannot be used to monitor time dependent phenomena. Time resolution in an EXAFS experiment can be achieved using the dispersive EXAFS technique [13] or by the application of the quick-scanning EXAFS (QEXAFS) mode [14]. In the latter method, the monochromator is slewed continuously at a high speed by means of microstepper motors and each data point is integrated for typically $0.01-0.2 \mathrm{~s}$, so that a complete spectrum can be obtained in less than one minute or even a couple of seconds only. In this work, we used the QEXAFS implementation at the RÖMO II beamline to show that QEXAFS using total external reflection enables in situ structural investigations of electrode surfaces with time resolution. The anodic oxidation of silver has been chosen as a model system in order to demonstrate the capabilities of this new EXAFS tool in electrochemical research.

\section{EXPERIMENTAL SECTION}

Thin silver films (thickness $\approx 300 \mathrm{~nm}$ ) were sputter deposited onto glass substrates and subsequently mounted in an electrochemical cell for in situ studies with X-rays; details of this cell are given in reference [15]. All electrochemical preparations were performed in $1 \mathrm{M} \mathrm{NaOH}(\mathrm{pH} 13.8)$, all potentials given in this paper are quoted against the standard hydrogen electrode (SHE). The reflectivity EXAFS data were collected in situ under potential control in the vicinity of the Ag-K edge (25.514 keV) using a double-crystal monochromator with two flat Si (311) crystals. The experiments were performed at the RÖMO II beamline (bending magnet) at the DORIS III storage ring at HASYLAB (Hamburg, Germany) operating with $\approx 75$ $100 \mathrm{~mA}$ of stored positron current. The glancing angle was adjusted by a stepper motor and the incident X-ray beam was collimated by a $50 \mu \mathrm{m}$ slit. Incident and reflected intensities were measured by means of Argon and Krypton filled ionization chambers. A silver foil, crystalline $\mathrm{Ag}_{2} \mathrm{O}$ and $\mathrm{AgO}$ powders pressed in polyethylene were measured in transmission to obtain standard spectra. Further details of the experimental arrangement are given elsewhere [16]. 


\section{RESULTS AND DISCUSSION}

Two in situ reflectivity EXAFS spectra $\left(\Theta=0.08^{\circ}\right)$ of a reduced silver electrode $\left(U_{\mathrm{p}}=-0.3 \mathrm{~V}\right)$ are compared in Figure 1. The reflectivity drop at about $25.5 \mathrm{keV}$ is connected to the $\mathrm{K}$-edge absorption coefficient of silver and the oscillations above the edge are related to EXAFS. While the conventional point-by-point spectrum took 14 min, the QEXAFS-scan was recorded during $63 \mathrm{~s}$ with no significant sacrifice of the S/N ratio in the EXAFS region as one might conclude from the $k^{1}-$ weighted reflectivity oscillations which are depicted in the insert of Figure 1. Therefore, QEXAFS in the reflection mode permits real time EXAFS studies of electrode surfaces under in situ electrochemical conditions with a time scale of about 1 minute.

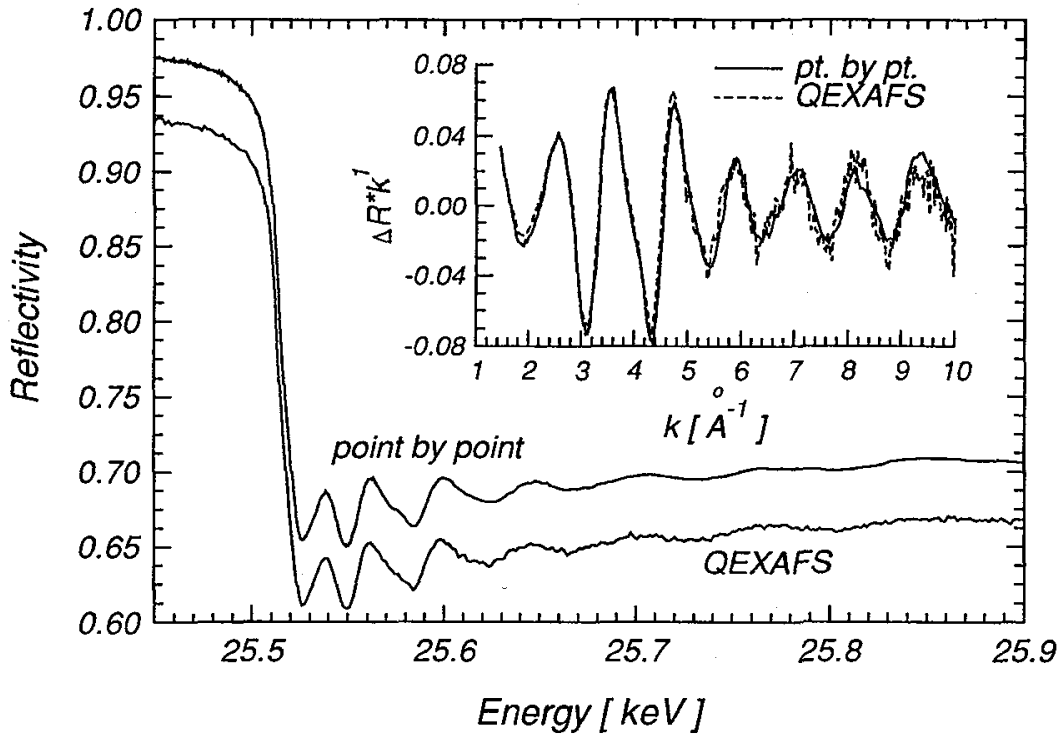

Figure 1: Conventional point-by-point mode $(14 \mathrm{~min} / \mathrm{scan})$ and QEXAFS mode $(63.5 \mathrm{~s} / \mathrm{scan}, 0.2 \mathrm{~s} /$ data point $)$ reflectivity EXAFS spectra (glancing angle $\theta=0.08^{\circ}$ ) obtained in situ from a reduced silver electrode in $1 \mathrm{M} \mathrm{NaOH}$ in the vicinity of the Ag-K edge. The QEXAFS data were shifted to lower reflectivities for a better comparison. In the insert, the $k^{1}$-weighted reflectivity fine structure data of both spectra are depicted.

In Figure 2a, a number of in situ quick scanning EXAFS reflectivity spectra (glancing angle $\Theta=0.08^{\circ}, 44.2 \mathrm{~s} / \mathrm{scan}$, $0.1 \mathrm{~s} /$ data point) are presented for the initial stages of anodic oxidation of a silver electrode. After completion of the first scan, the potential was stepped from $-0.3 \mathrm{~V}$ to $+0.4 \mathrm{~V}$ (SHE); the resulting current transient related to the surface oxide formation is depicted in the insert of Figure 2a. Obviously, the shape of the reflectivity spectra slowly changes with time. The magnitude of the Fourier-Transform (FT) of the $k^{1}$-weighted reflectivity fine structure data is shown in Figure $2 \mathrm{~b}$. These FT's are dominated by a strong peak at $r \approx 0.27 \mathrm{~nm}$ belonging to the first $\mathrm{Ag}-\mathrm{Ag}$ coordination of silver metal; due to the resonating behaviour of the photoelectron backscattering amplitude, this peak exhibits a double-peaked structure [17, 18]. A weak oxide contribution increasing with time is visible at $r \approx 0.13 \mathrm{~nm}$, corresponding to the first $\mathrm{Ag}-\mathrm{O}$ shell of the growing $\mathrm{Ag}(\mathrm{I})$-oxide film. Due to the relatively low S/N-ratio of the reflectivity data, the FT-data above $r \approx 0.35 \mathrm{~nm}$ should not be correlated with coordination shells of the metal or oxide for the presented experiment. The magnitude of the Fourier-Transform of the first coordination shell of the oxide and the metal substrate are depicted as a function of time in Figure 3a. Obviously, the intensity of the oxide contribution increases with time, while the height of the metal substrate peak significantly decreases. For a further evaluation of the experimental data, reflectivity spectra of oxide covered silver electrodes were calculated using a procedure which is described in detail in refs. $[11,19,20]$. Reflectivity spectra were obtained as energy dependent Fresnel reflectivities using the indices of refraction of $\mathrm{Ag}$ metal and $\mathrm{Ag}_{2} \mathrm{O}$. The latter were extracted from transmission EXAFS spectra of a silver metal foil and $\mathrm{Ag}_{2} \mathrm{O}$ powder, respectively $[19,20]$. For a given glancing angle, a variation of the thickness of the oxide layer results in considerable changes of the metal and oxide contributions in the Fourier-Transform of the calculated spectra; i.e. the experimental data can be fitted by adjusting the parameters of the calculated spectrum properly so that a close fit is achieved. The oxide thicknesses obtained for two potential step experiments are presented in Figure $3 \mathrm{~b}$. In agreement with results recently obtained by ellipsometry [3], a linear relation between the oxide film thickness and the square root of time is observed for both potentials. The slope of the straight line, i.e. the growth rate constant, increases with potential. Parabolic growth behaviour in a potential step experiment is an indicator of film formation controlled by diffusion through the growing oxide layer. 
Furthermore, the comparison of the thickness values obtained from the reflectivity EXAFS data evaluation with those of charge balance calculations shows that only a fraction $(\approx 30-40 \%)$ of the total charge is used for the oxide formation.
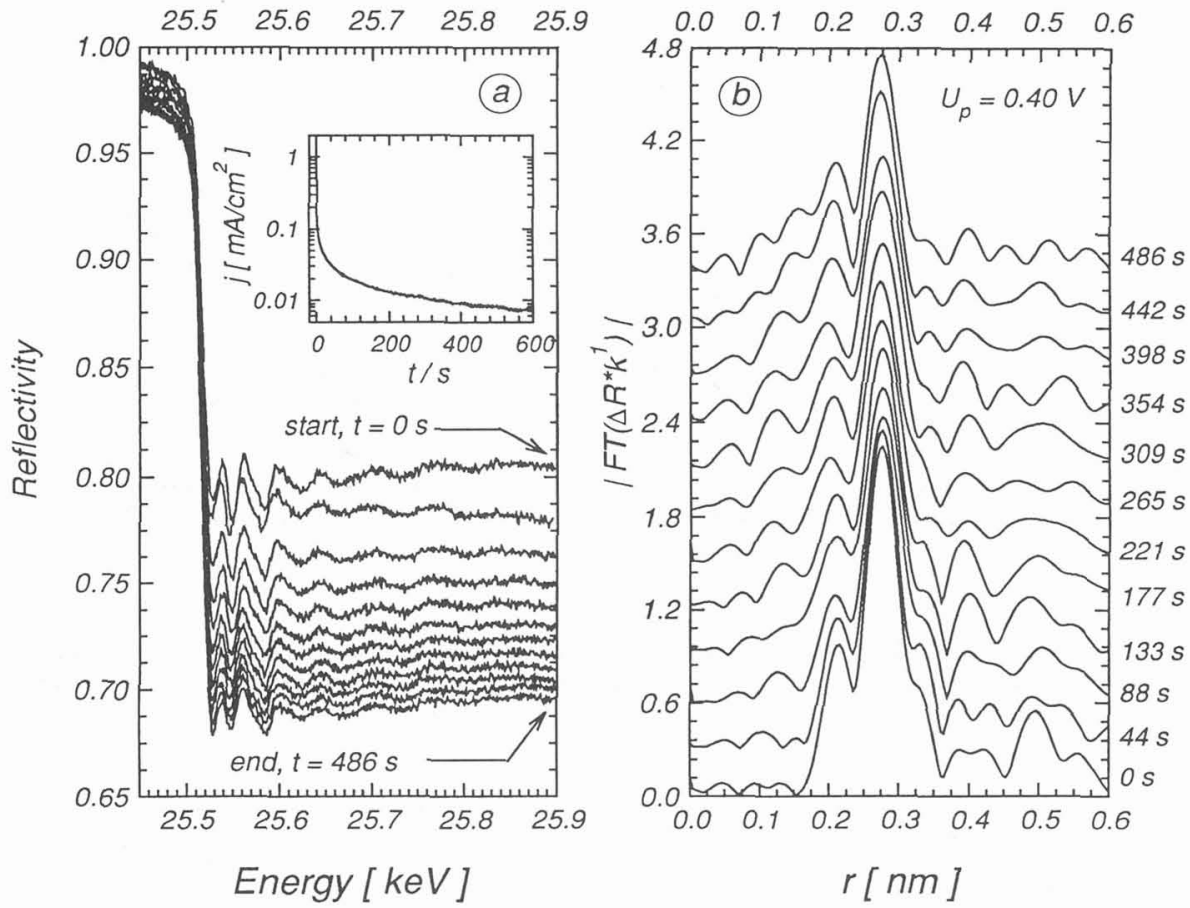

Figure 2: (a) Time dependent in situ reflectivity spectra for a silver electrode in $1 \mathrm{M} \mathrm{NaOH}$ and a glancing angle $\Theta=0.08^{\circ}$. The shown reflectivity spectra were measured in $44.2 \mathrm{~s}$ with an integration time of $0.1 \mathrm{~s}$ for each data point. While the first QEXAFS scan was recorded at a polarization potential $U_{\mathrm{p}}=-0.3 \mathrm{~V}$, the following reflectivity spectra were recorded after a potential step to $U_{\mathrm{p}}=+0.4 \mathrm{~V}$ (SHE); the resulting current transient related to the surface oxide formation is depicted in the insert of Figure $2 \mathrm{a}$. (b) Fourier-Transform magnitude (FT) of the $k^{1}$ - weighted reflectivity oscillations of Figure 2a (not phase shift corrected) over a k-range of $1.73-9.24 \AA^{-1}$. The small peak at $r \approx 0.13 \mathrm{~nm}$ belongs to the first Ag-O coordination of the oxide and the strong peak at $\approx 0.27$ $\mathrm{nm}$ corresponds to the first $\mathrm{Ag}-\mathrm{Ag}$ shell in metallic silver.

More complex changes of the near range order structure are observed if thick $\mathrm{Ag}_{2} \mathrm{O}$ layers formed potentiostatically at +0.7 $\mathrm{V}$ are submitted to a further potential step to a higher potential. In Figure $4 \mathrm{a}$, reflectivity spectra related to a potential step from $+0.7 \mathrm{~V}$ to $+0.8 \mathrm{~V}$ are presented. Corresponding to the increase of the electrochemical current (see insert of Figure 4a), the reflectivity decreases strongly even before the absorption edge as can be seen in the second scan. The current transient shows the characteristics of a nucleation and growth controlled process $[2,21]$. Further modifications of the reflectivity spectra are visible in the following scans. As can be seen in Figure $4 \mathrm{~b}$, distinct changes of the shape and the intensity of the individual coordination spheres are observed in the related Fourier-Transforms. While the FT of the first spectrum is representative for crystalline $\mathrm{Ag}_{2} \mathrm{O}$ [16], the second FT already contains strong contributions at $\approx 0.32 \mathrm{~nm}$ which are characteristic for AgO [22]. The thickness of the AgO-layer exceeds $30 \mathrm{~nm}$ after $\approx 40 \mathrm{~s}$ as estimated from the integration of the current transient. Due to the information depth of about $10 \mathrm{~nm}$, the following reflectivity spectra only contain information about the near surface region of the electrochemically formed AgO layer. Therefore the modifications of the short range order structure which are visible in the subsequent scans can be interpreted in terms of a slow phase formation within the oxide. Although less detailed, the last presented spectrum is very similar to those reported from crystalline AgO [22]. The strongest peaks at $\approx 0.15 \mathrm{~nm}$ and $\approx 0.32$ $\mathrm{nm}$ arise from $\mathrm{Ag}-\mathrm{O}$-shells at $0.203 \mathrm{~nm}$ and $0.218 \mathrm{~nm}$ and $\mathrm{Ag}-\mathrm{Ag}$ coordinations at $0.340 \mathrm{~nm}$ and $0.348 \mathrm{~nm}$, respectively. Due to the low signal to noise ratio of the QEXAFS data, the individual coordination shells cannot be separated completely in these spectra, in contrast to step by step transmission EXAFS results [22]. According to recently published data, electrochemically formed AgO-layers are oxygen deficient compared to $\mathrm{AgO}$ prepared chemically by oxidation of $\mathrm{AgNO}_{3}$ with $\mathrm{Na}_{2} \mathrm{~S}_{2} \mathrm{O}_{8}$ in alkaline solutions [22]. These experiments also suggested the presence of an intermediate phase such as $\mathrm{Ag}_{4} \mathrm{O}_{3}$ during the electrochemical oxidation of $\mathrm{Ag}$ or $\mathrm{Ag}_{2} \mathrm{O}$ to $\mathrm{AgO}$ [22]. According to these results, the observed structural changes may be interpreted in terms of an oxygen incorporation into the $\mathrm{AgO}$-lattice increasing with time. Although characteristic $\mathrm{AgO}$-features are already visible in the second spectrum, the structure of the anodic layer is different compared to that of crystalline AgO. While the initial structure seems to be more disordered, the incorporation of oxygen yields a time dependent evolution of the 
peaks in the Fourier-Transform extending from $\approx 0.18 \mathrm{~nm}$ to $\approx 0.3 \mathrm{~nm}$. These peaks are belonging to Ag-O coordination shells at $0.265 \mathrm{~nm}, 0.277 \mathrm{~nm}, 0.290 \mathrm{~nm}$ and $\mathrm{Ag}-\mathrm{Ag}$ shells at $0.325 \mathrm{~nm}$ and $0.336 \mathrm{~nm}$. We can therefore conclude that the amount of oxygen which is incorporated into the $\mathrm{Ag}_{2} \mathrm{O}$-oxide lattice during its electrochemical oxidation to $\mathrm{AgO}$ increases with time.
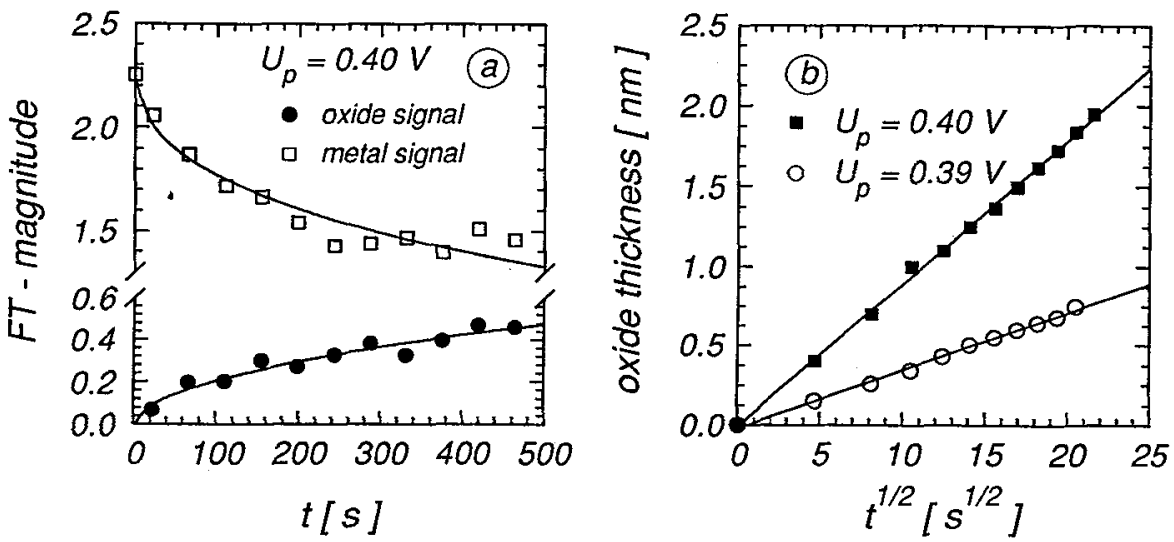

Figure 3: Evaluation of the in situ QEXAFS measurements during the electrochemical oxide formation in $1 \mathrm{M} \mathrm{NaOH}$ as a function of time: (a) Magnitude of the Fourier-Transform related to the first Ag-Ag shell of the silver metal substrate at $r \approx 0.27 \mathrm{~nm}$ ( $\square$ ) and the Ag-O shell of the silver oxide overlayer at $r \approx 0.13 \mathrm{~nm}(\ominus)$ for $U_{\mathrm{p}}=0.40 \mathrm{~V}$. (b) Increase of the oxide layer thickness with square root of time as derived from the QEXAFS data for two potentials.
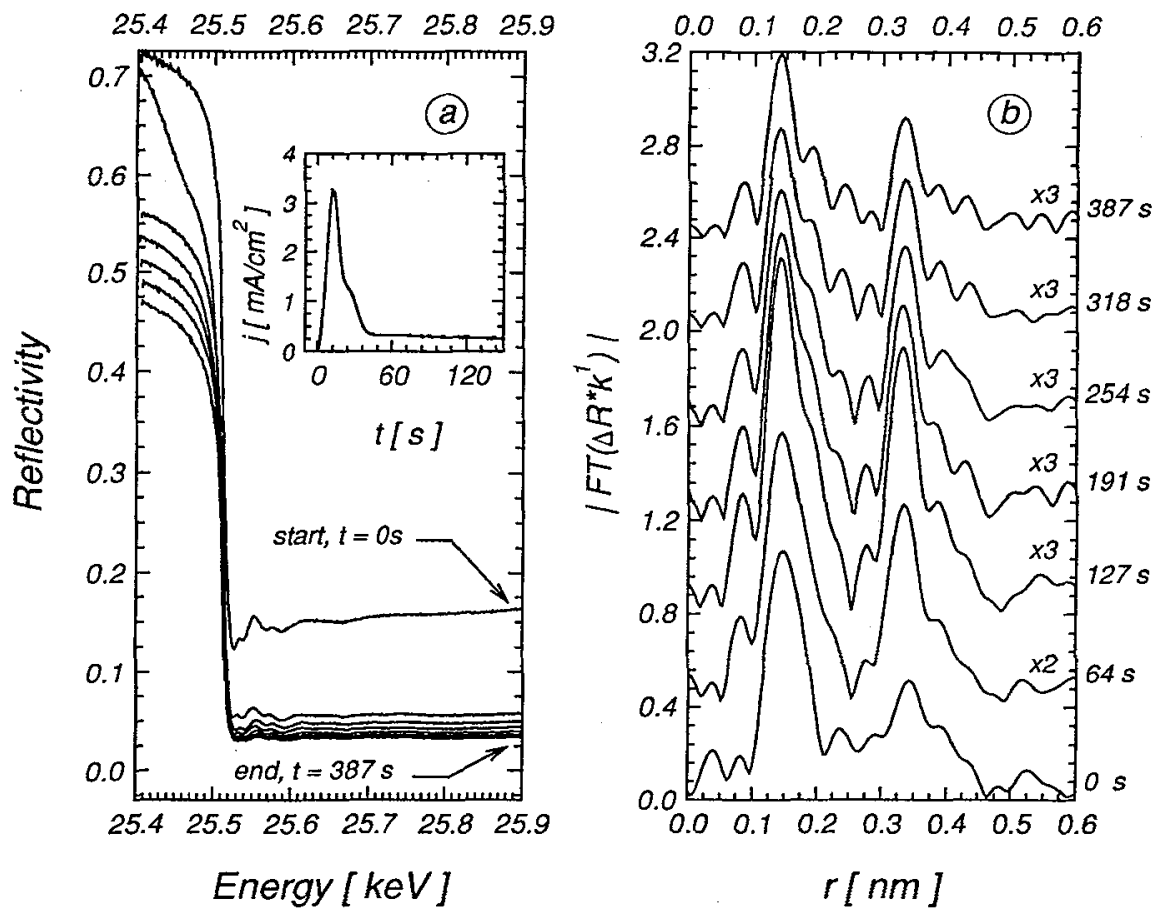

Figure 4: (a) Time dependent reflectivity spectra for the further oxidation of an $\mathrm{Ag}_{2} \mathrm{O}$-layer (glancing angle $\Theta=0.09^{\circ}, 63.5 \mathrm{~s} / \mathrm{scan}$, $0.15 \mathrm{~s} /$ data point). After completion of the first scan, the potential was stepped from $+0.7 \mathrm{~V}$ to $+0.8 \mathrm{~V}$ (SHE); the tesulting current transient related to the oxidation of $\mathrm{Ag}_{2} \mathrm{O}$ is depicted in the insert of Figure 3a. (b) Magnitude of the Fourier-Transform (FT) of the $k^{1}$ - weighted reflectivity fine structure data of Figure 3a (not phase shift corrected). Transformation over the $k$-range of 1.80 $10.04 \AA^{-1}$. 
If the kinetics of the electrochemical reactions are faster than those described above, the time required for a complete EXAFS spectrum is too long. In Figure 5, a number of near edge reflectivity spectra (XANES) are presented. Each QEXAFS scan took $12.7 \mathrm{~s}$ and the glancing angle was set to $\Theta=0.09^{\circ}$, resulting in an information depth of about $10 \mathrm{~nm}$. After completition of the first scan, the potential was stepped from $-0.3 \mathrm{~V}$ to $+0.7 \mathrm{~V}$; the simultaneously measured current transient is depicted in the insert of Figure 5. The thickness of the oxide layer (estimated from the electrochemical charge) is larger than the information depth after ca. $1.1 \mathrm{~s}$, therefore the reflectivity XANES spectra only contain near range order structural information about the growing $\mathrm{Ag}(\mathrm{I})$-oxide layer. While the first spectrum reveals the XANES of metallic silver, the measured spectra of the oxidized electrode are very similar to those calculated for crystalline $\operatorname{Ag}_{2} \mathrm{O}$ and do not change noticeably with time. In addition, the evaluation of reflectivity EXAFS spectra for this potential clearly show that the near range order of the electrochemically formed $\mathrm{Ag}(\mathrm{I})$ oxide is very similar to that of polycrystalline $\mathrm{Ag}_{2} \mathrm{O}$ [8]. From the presented QEXAFS data we can therefore conclude that $\mathrm{Ag}_{2} \mathrm{O}$ crystallites with a well defined short range order are formed immediately after the potential step to $+0.7 \mathrm{~V}$.

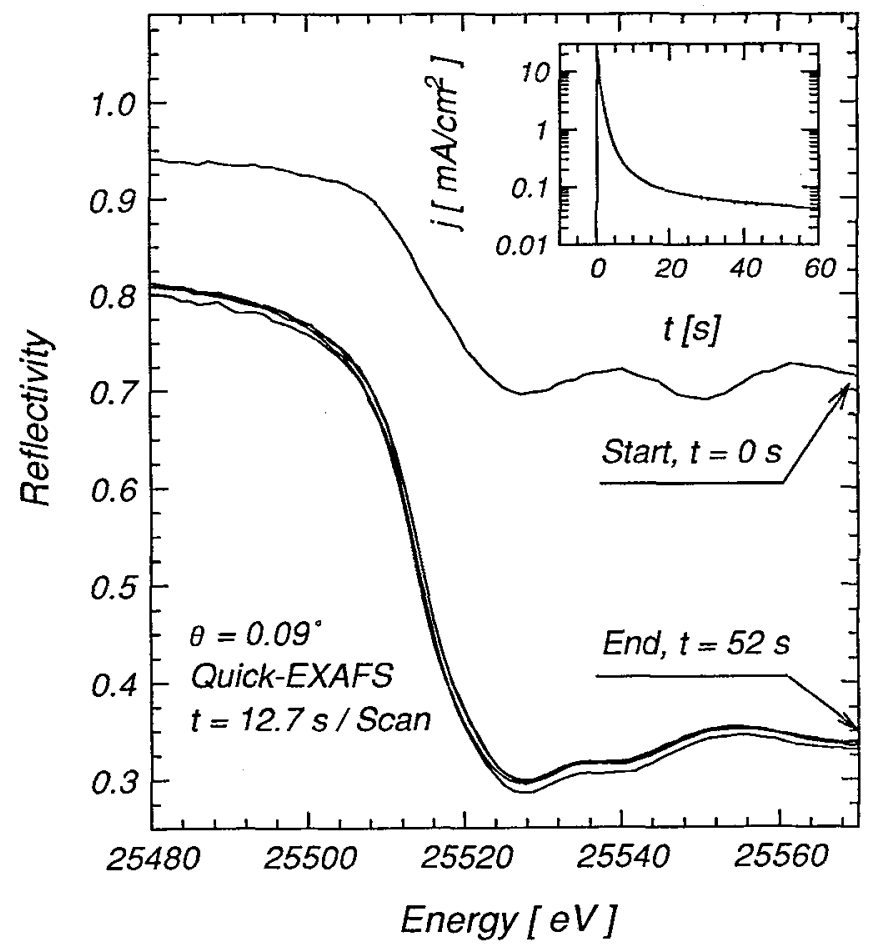

Figure 5: Time dependent in situ reflectivity spectra (near edge region) for a silver electrode in $1 \mathrm{M} \mathrm{NaOH}$ and a glancing angle $\Theta=0.09^{\circ}$. The shown reflectivity XANES spectra were measured in $12.7 \mathrm{~s}$ with an integration time of $0.15 \mathrm{~s}$ for each data point. While the first QEXAFS scan was recorded at a polarization potential $U_{\mathrm{p}}=-0.3 \mathrm{~V}$, the following reflectivity spectra were recorded after a potential step to $U_{\mathrm{p}}=+0.7 \mathrm{~V}$ (SHE). The current transient related to the silver oxide formation is depicted in the insert.

\section{CONCLUSIONS}

The combination of the quick-scanning EXAFS technique and the grazing incidence geometry offers new possibilities for time resolved structural evaluation of electrode surfaces under potential controlled conditions, including thin film growth, electrochemical phase formation kinetics and ageing effects. For the silver / silver oxide system investigated in the present study, a parabolic growth law was determined from grazing incidence QEXAFS data measured during the initial stages of the anodic oxidation of $\mathrm{Ag}$ in $1 \mathrm{M} \mathrm{NaOH}$. For more anodic oxidation potentials, time dependent reflectivity XANES data suggest the formation of a crystalline $\mathrm{Ag}_{2} \mathrm{O}$ phase during the first few seconds of a potential step experiment. The incorporation of oxygen into the $\mathrm{Ag}_{2} \mathrm{O}$-lattice during the electrochemical formation of $\mathrm{AgO}$ at more anodic potentials could be followed with a time resolution of about $1 \mathrm{~min}$. Similar to transmission QEXAFS experiments, it should in principle be possible to reduce the data acquisition time to only a couple of seconds by using a high intensity wiggler beamline. Such an improvement of the time resolution for the reflection geometry would also allow larger scan ranges in moderately short time periods. Accompanied by an increased signal to noise ratio, more detailed structural information of the electrode surfaces would then be accessible. In addition, DEXAFS at grazing incidence might also be feasible for near surface structural investigations [23]. 


\section{References}

[1] Wales C.P. and Burbank J., J. Electrochem. Soc. 106 (1959) 855-890.

[2] Droog J.M.M. and Huisman F., J. Electroanal. Chem. 115 (1980) 211-224.

[3] Mayer S.T. and Müller R.H., J. Electrochem. Soc. 135 (1988) 2133-2142.

[4] Droog J.M.M., J. Electroanal. Chem. 115 (1980) 225-233.

[5] Burstein G.T. and Newman R.C., Electrochim. Acta 25 (1980) 1009-1013.

[6] Lopez Teijelo M., Vilche J.R. and Arvia A.J., J. Electroanal. Chem. 131 (1982) 331-339.

[7] Lopez Teijelo M., Vilche J.R. and Arvia A.J., J. Electroanal. Chem. 162 (1984) 207-224.

[8] Hecht D., Borthen P. and Strehblow H.-H., Surf. Sci. 365 (1997) 263-277.

[9] Koningsberger D.C., Prins R., X-ray absorption: Principles, Applications, Techniques of EXAFS, SEXAFS and XANES, Wiley: New York, 1988.

[10] Parratt L.G., Phys. Rev. 95 (1954) 359-369.

[11] Borthen P. and Strehblow, this issue.

[12] Cortes R., Froment M., Hugot-Le Goff A. and Joiret S., Corros. Sci. 31 (1990) 121-127.

[13] Fontaine A., Dartyge E., Itié J. P., Jucha A., Polian A., Tolentino H., Tourillon G, Topics in Current Chemistry 143 (1989) 179-203.

[14] Frahm R., Rev. Sci. Instr. 60 (1989) 2515-2518.

[15] Borthen P. and Strehblow H.-H., Hasylab Annual Report 1993, p. 883-884.

[16] Hecht D., Borthen P. and Strehblow H.-H., J. Electroanal. Chem. 381 (1995) 113-121.

[17] Mott N.F. and Massey H.S.W., The Theory of Atomic Collisions, 3rd ed.; Clarendon: Oxford, $1965 ;$ p. 562.

[18] Dalba G., Fornasini P., Rocca F. and Mobilio S., Phys. Rev. B41 (1990) 9668-9675.

[19] Borthen P. and Strehblow H.-H., Physica B208\&209 (1995) 421-422.

[20] Borthen P., PhD-thesis, Universität Düsseldorf 1996

[21] Salvarezza R.C., Gòmez Becerra J. and Arvia A.J., Electrochim. Acta 33 (1988) 1753-1759.

[22] Mansour A.N., J. Phys. Chem. 94 (1990) 1006-1010.

[23] Mimault J., Cortes R., Dartyge E., Fontaine A., Jucha A, and Sayers D., "Efficiency of the Energy Dispersive Configuration for X-Ray Absorption Measurement by Total Reflection", in EXAFS and Near Edge Structure III, Eds. Hodgson K. O., Hedman B. and Penner-Hahn J. E., Springer: Berlin 1984, pp. 479-481. 